\title{
Garp linyitleri işletmesi (GLI) Tunçbilek göletlerinde bulunan tesis artıklarının karakterizasyonu
}

\section{Characterization of the waste materials in the ponds of western lignite company (WLC) at Tunçbilek}

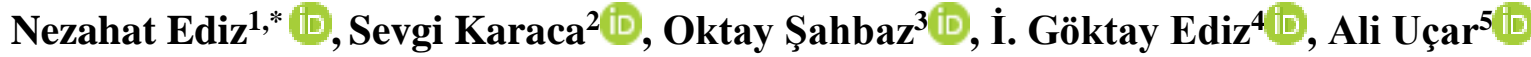 \\ 1,2,3,4,5 Kütahya Dumlupınar Üniversitesi, Maden Mühendisliği Bölümü, 43000, Kütahya, Türkiye
}

\section{Özet}

Bu çalışmada, Garp Linyitleri İşlemesi (GLİ)’ne ait şlam göletlerinde bulunan malzemelerin değerlendirilebilirliğinin belirlenmesi ve çevresel sorunlarının önlenebilmesi için karakterizasyon çalışmaları yapılmıştır. Yapılan deneyler ile 4 No'lu, Beke-Yörgüç ve 6/C şlam göletlerindeki malzemelerin tane boyut dağılımları, fiziksel, kimyasal (elementel, nem, kül, kükürt, 1sıl değer), mineralojik ve termal özellikleri belirlenmiştir. $\mathrm{Bu}$ testler hem göletlerdeki malzemelerin orijinal boyutlarında hem de $0.038 \mathrm{~mm}$ altındaki boyutlarda yapılmıştır. Elementel analizlerde hem orijinal hem de $0.038 \mathrm{~mm}$ altındaki gölet malzemelerindeki majör oksitlerin $\mathrm{SiO} 2, \mathrm{Al} 2 \mathrm{O} 3, \mathrm{Fe} 2 \mathrm{O} 3, \mathrm{CaO}, \mathrm{MgO}, \mathrm{K} 2 \mathrm{O}$ ve $\mathrm{SO} 3$ olduğu belirlenmiştir. 4 No'lu, Beke-Yörgüç ve 6/C göletlerinin kül içerikleri sırasıyla \%68.01, \%62.73 ve $\% 59.71$ olarak belirlenmiştir. Orijinal ve $0.038 \mathrm{~mm}$ altı malzemelerin mineralojik analizleri sonucunda tüm numunelerin kuvars, muskovit/illit, montmorillonit, kristobalit, jips, kaolinit minerallerinden oluştuğu tespit edilmiştir. DTA-TG analizlerine göre ise tüm malzemelerde, $200-400^{\circ} \mathrm{C}$ arasında organik maddelerin yanma reaksiyonlarının meydana geldiği, $690-750^{\circ} \mathrm{C}$ arasında ise kömürdeki kükürdün uzaklaştığı belirlenmiştir.

Anahtar kelimeler: Karakterizasyon, Kömür, Şlam göleti

\section{Giriş}

Organik tortul kayaç olan kömür, çoğunlukla minerallerden oluşan inorganik maddeleri ve maseral yapıdaki yanıcı organik maddeleri içerir. Kömür belirli düzeylerde heterojendir. En basit düzeyde, organik ve inorganik fazların bir karışımıdır, ancak kömürün mineral maddesi, oluştuğu bitkinin inorganik bileşenlerinden, diğer organik maddelerden ve kömür yatağına taşınan farklı yapı ve serbestleşme karakteri olan inorganik bileşenlerden meydana gelmiştir [1].

Kömür hazırlama, ham kömürden safsızlıkların (inorganik madde) içeriğini azaltarak değerini yükseltir. Kömür hazırlama işlemleri sırasında kül yapıcı maddeler kömürden tamamen uzaklaştırılamaz, ancak daha düşük inorganik madde içeriğine sahip olan kısım, daha yüksek inorganik madde içeriğine sahip olan kısımdan ayrılır [1].

\section{Abstract}

In this research, some characterization studies were carried on the samples taken from the waste ponds of Western Lignite Company (WLC) in order to define utilization possibilities and prevent environmental problems of these materials. During the investigation, particle size distribution, physical and chemical properties (elemental analysis, humidity and sulphur content and calorific value) as well as mineralogical and thermal properties of the materials from the waste ponds called Number-4, Beke Yörgüç and 6/C were determined. From the elemental analysis of waste materials made both on the original samples and on the materials below $0.038 \mathrm{~mm}$, it was understood that major oxides were comprised of $\mathrm{SiO} 2$, $\mathrm{Al} 2 \mathrm{O} 3, \mathrm{Fe} 2 \mathrm{O} 3, \mathrm{CaO}, \mathrm{MgO}, \mathrm{K} 2 \mathrm{O}$ and $\mathrm{SO} 3$. The ash content of the waste materials was found to be $68.01 \%, 62.73 \%$ and $59.71 \%$ for the waste ponds of Number-4, Beke Yörgüç and $6 / \mathrm{C}$, respectively. Mineralogical analysis made showed that both the original samples and the materials below 0.038 $\mathrm{mm}$ were comprised of minerals such as quarts, muscovite/illite, montmorillonite, kristobalite, gypsum, kaolinite. DTA-TG analysis also proved that combustion reactions of the organic matters were occurred at 200$400^{\circ} \mathrm{C}$ while sulphur within the coal was removed at the temperatures of $690-750^{\circ} \mathrm{C}$.

Keywords: Characterization, Coal, Slime pond

Kömür yıkama yöntemleri iri ve ince boyutlu kömürler için farklıdır. İri ve orta boyutlar için gravite yöntemleri, ince boyutlar için ise genelde flotasyon yöntemi uygulanır $[2,3]$. Kömür hazırlamada ince kömür deyimi $0.5 \mathrm{~mm}$ 'nin altındaki boyutlar için kullanılırken, $(-6+0.5)(-10+0.5)$ ya da ($18+0.5) \mathrm{mm}$ orta boy ve 6,10 veya $18 \mathrm{~mm}$ 'nin üstü ise iri kömür olarak adlandırılır. Kömür yıkama işlemleri tane boyutu yanında kül, kükürt ve nem içeriği gibi etmenlere göre de değişir [4].

Maden ve kömürlerden gang minerallerinin uzaklaştırılması için kurulan cevher hazırlama ve kömür yıkama tesislerinden çıkan atıklar, depolama ve yer sorunu ortaya çıkarmakta ve zamanla çevreye zarar vermektedirler [5]. Kömür endüstrisinin çevreye etkileri madenlerden kömür çıkarma, kömür hazırlama işlemleri, kömür nakliyatı, kömür yakma, atık depolama ve atık bertarafı gibi çeşitli

\footnotetext{
* Sorumlu yazar / Corresponding author, e-posta / e-mail: nezahat.ediz@dpu.edu.tr (N. Ediz)

Geliș / Recieved: 19.11.2020 Kabul / Accepted: 04.03.2021 Yayımlanma / Published: 27.07.2021

doi: $10.28948 /$ ngmuh. 826789
} 
aşamalarda görülse de, bu etkileri başlıca iki ana grupta incelemek mümkündür.

1. Kömür madenciliği sırasında oluşan çevresel etkiler: Kömür madenciliği; toprak örtüsünün bozulmasına, yüzey ve yeraltı suları ile içme suyu kaynaklarının kirlenmesine, su ve toprak habitatlarının bozulmasina ve hava kalitesinin olumsuz etkilenmesine neden olan bir faaliyettir.

2. Kömür yıkama (lavvar) ve hazırlama sırasında oluşan çevresel etkiler: Kömür yıkama faaliyetleri sonucu ortaya çıkan artıklardır. $\mathrm{Bu}$ artıklardan iri taneli olanlar (coarse tailings) genellikle açıkta yığınlar halinde depolanırken, daha sulu ve ince taneli olanlar atık barajlarına sevk edilmekte veya filtrelenmektedir. Bu artıklar doğal olarak radyoaktif maddeler de içerirler. Ayrıca pirit içermeleri halinde asidik su oluşumuna yol açabilirler. Ayrıca kömür hazırlamada flotasyon ve flokülasyon aşamalarında çeşitli kimyasallar kullanıldığı takdirde, bu atıklarda çevre için sakıncalı olabilecek kirleticiler de bulunabilmektedir.

Sulu ve ince taneli artıklar kimyasal ve zararlı metal içermeleri, ince taneli olmaları, asit maden drenajına neden olmaları, büyük miktarlarda olmaları nedeniyle çok fazla yer işgal etmeleri ve görsel kirlilik yaratmaları nedenleri ile çevre bilincinin her geçen gün arttığı dünyada ve ülkemizde bu atıkların bertaraf edilmesi önemli bir konu olarak karşımıza çıkmaktadır.

1993 yılında devreye alınan ve GLİ tarafından işletilen Ömerler ile ülkemizin en eski lavvarlarından biri olan ve özel sektör tarafindan ișletilen Tunçbilek Lavvarları'nda da uygulanan gravite prosesleri sirasında bu artıklar oluşmaktadır. Ayrıca tesislerin civarlarında daha önceki yıllarda bu artıkların depolandığı iki adet havuz ve iki adet de (4 No'lu ve Beke-Yörgüç Şlam göletleri) açık ocak deposu bulunmaktadır. Tesislerden halen başka bir açık ocak imalat sahasına (6/C) artık şarjı devam etmektedir. GLİ'ye ait göletlerde şimdiye kadar 20 milyon ton şlam birikmiştir ve bu iki lavvardan halen yılda 2.5 milyon $\mathrm{m}^{3}$ şlam birikmeye devam etmektedir [6].

Kömür yıkama tesisi atıkları ile ilgili yapılan çalışmalar incelendiğinde, çalışmaların genellikle sulu atıklardan kömürün kazanılmasına ve bu atıkların susuzlandırılmasına yönelik olduğu dikkat çekmektedir [7-14].

Kömür yıkama atıklarının değerlendirilmesi ile ilgili yapılmış sınırlı kalmıştır. Sabah [15] Tunçbilek kömür hazırlama tesisi atığının tuğla bünyelerde kullanılabilirliğini araştırdığ kömür atığı karıştırmış ve farklı sıcaklıklarda sinterleyerek elde ettiği tuğla bünyelere çeşitli performans testleri uygulamıştır. Deneyler sonucunda $950^{\circ} \mathrm{C}$ 'de sinterlenen, \%2.5 kömür atığı katkılı tuğlaların basınç dayanımlarının gözenekliliğinin yüksek olduğu, dolayısıyla hafif yapı elemanı olarak kullanılabileceğini tespit etmiştir.

İnce [16] GLİ Tunçbilek üretim sahasında 4 No'lu ocak imalat boşluğunda bulunan lavvar atığını $(-0.038 \mu \mathrm{m})$ tuğla kiline katkı maddesi olarak kullanmıştır. Tuğla kiline farklı oranlarda ilave edilen atık malzeme ile elde edilen bünyeler, farklı sıcaklıklarda sinterlenmiş ve çeşitli testlere tabi tutulmuştur. Deneyler sonucunda $1050^{\circ} \mathrm{C}$ sicaklıkta sinterlenmiş ve $\% 50$ kömür atığ katkılı olan tuğla bünye ile optimum değerler elde edilmiştir.

Türkiye Kömür İşletmeleri Kurumu tarafından desteklenen ve proje yürütücülüğ̈̈ TÜBİTAK MAM Malzeme Enstitüsü tarafından gerçekleştirilen çalışmada, kömür yıkama faaliyetleri sonucu oluşan şlam atıklarının alternatif bir hammadde olarak tuğla ve çimento sektöründe değerlendirilebileceği belirtilmiştir [17].

$\mathrm{Bu}$ çalışmada, GLİ bünyesinde faaliyet gösteren Lavvar tesislerinin kurulumundan günümüze kadar ortaya çıkan ve değerlendirilebilecek durumda olan tesis artıklarının karakterizasyonu yapılmıştır. Böylece, çevre sorunlarına neden olan bu malzemelerin değerlendirilebilirliğine 1 şı tutulacaktır.

\section{Materyal ve metot}

Deneylerde kullanılan malzemeler GLİ İşletmesi'ne ait 4 No'lu, Beke-Yörgüç ve 6/C olarak adlandırılan artık göletlerinden alınmıştır (Şekil 1). Artık sahalarından işletme tarafından alınan bu malzemeler DPÜ Maden Mühendisliği Bölüm Laboratuvarına getirilmiş ve ayrı ayrı karıştırılarak homojenize edilmiştir. Yaklaşık olarak $400 \mathrm{~kg}$ (4 No'lu), 150 $\mathrm{kg}$ (Beke-Yörgüç) ve $150 \mathrm{~kg}$ (6/C) olan malzemeler, numune bölme işlemleri ile bölünerek deneysel çalışmalarda kullanılmak üzere depolanmıştır.

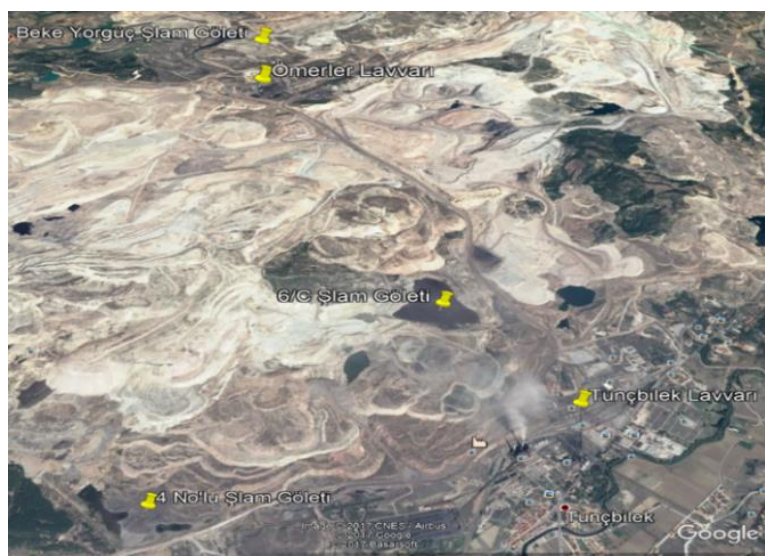

Şekil 1. 4 Nolu, Beke-Yörgüç ve 6/C şlam göletleri ve Tunçbilek Lavvarı konumları

Karakterizasyon çalışmalarında, hem orijinal hem de organik maddelerin daha az bulunduğu $0.038 \mathrm{~mm}$ altındaki boyutlarda olan malzeme kullanılmıştır. Bu malzemelerin tane boyut, kimyasal (elementel, nem, kül, kükürt, 1sıl değer), mineralojik ve termal analizleri yapılmıştır. Göletlerden alınan numunelerin tane boyut analizleri Retsch marka eleklerle, elek dizisi olarak Tyler serisi ve işletmede kullanılan elek açıklıkları baz alınarak yapılmıştır. -0.038 mm numunelerin tane boyut analizleri ise Malvern marka Mastersizer 3000 cihazı kullanılarak gerçekleştirilmiştir. Malzemelerin elementel analizleri PANalytical marka Axios max model XRF cihazı ile yapılmıştır. Nem değerleri Moisture Analyzer AND ML-50 cihazında ölçülmüştür. Kül analizleri Nüve marka kül fırınında, kükürt analizi Leco SC 144 DR cihazında ve kalori ölçümleri IKA WERKE cihazında gerçekleştirilmiştir. Numunelerin mineralojik 
analizleri PANalytical marka ve Empyrean model XRD cihazı ile $\mathrm{Cu} \mathrm{K} \alpha\left(\lambda=1.54 \mathrm{~A}^{\circ}\right)$ 1şıması kullanılarak $2 \theta=5-70^{\circ}$ aralığında $2 \%$ dk çekim hızında yapılmıştır. Numunelerin 1 sıl davranışlarının belirlenmesinde ise SETERAM marka, labsys model TG-DTA cihazı kullanılmıştır. Ölçümler argon gazı ortamında kuru havada $35-1000{ }^{\circ} \mathrm{C}$ sicaklık aralığında $10{ }^{\circ} \mathrm{C} / \mathrm{dk}$ 1sıtma hızında yapılmıştır.

\section{Bulgular ve tartışma}

\subsection{Tane boyut analizi}

Göletlerden alınan orijinal boyutlardaki numunelerin boyut fraksiyonlarına göre madde miktarı dağılımını belirlemek amacıyla elek analizi çalışmaları yapılmış ve sonuçlar Şekil 2'de verilmiştir. $0.038 \mathrm{~mm}$ 'den ince numunelerin tane boyut analiz sonuçları ise Şekil 3'de verilmiştir. Ayrıca $0.038 \mathrm{~mm}$ altı numunelerin $\mathrm{d}_{10}, \mathrm{~d}_{50}$ ve $\mathrm{d}_{90}$ değerleri Tablo 1'de özetlenmiştir.

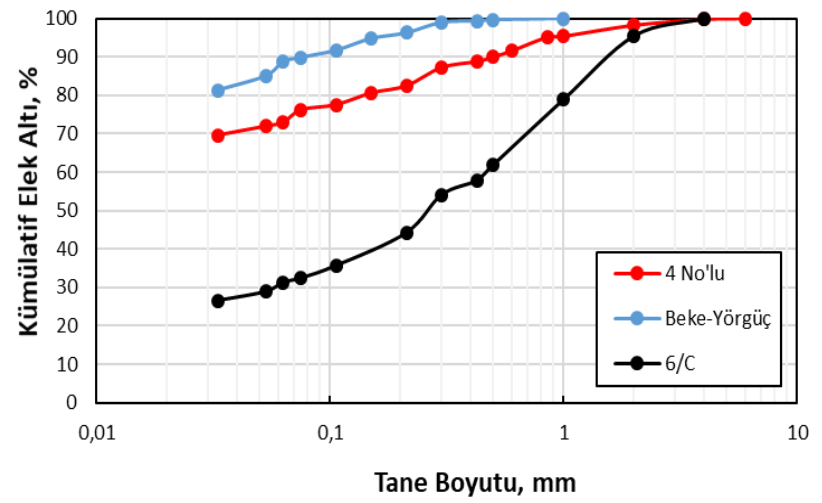

Şekil 2. Orijinal boyutlu malzemelerin tane boyut dağılımları

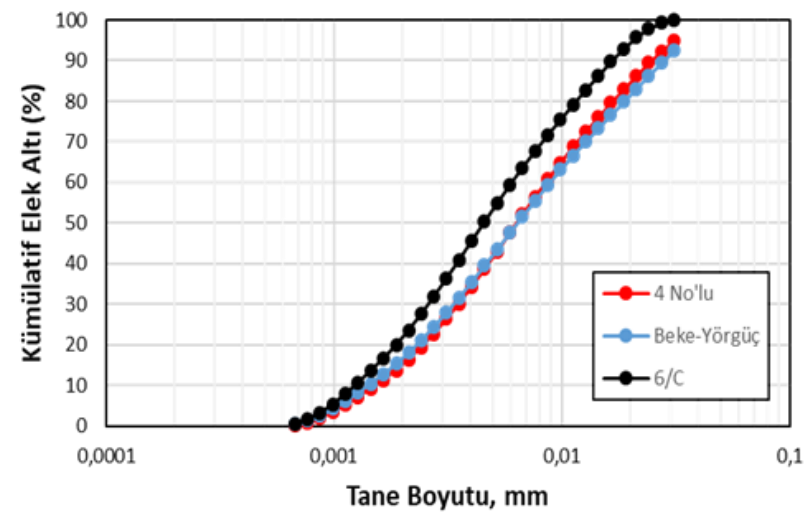

Şekil 3. $0.038 \mathrm{~mm}$ altı malzemelerin tane boyut dağılımları

Şekil 2 incelendiğinde gölet numunelerinin oldukça farklı tane boyut dağılımına sahip olduğu görülmektedir. Örneğin 4 No'lu gölet için en büyük tane boyutu $4 \mathrm{~mm}$, Beke-Yörgüç göleti için $0.5 \mathrm{~mm}$ ve $6 / \mathrm{C}$ göleti için $2 \mathrm{~mm}$ olarak belirlenmiştir. Şekil 3 incelendiğinde ise $-0.038 \mathrm{~mm}$ malzeme oranının da her gölet için az da olsa farklılık gösterdiği görülmektedir.
Tablo 1. $0.038 \mathrm{~mm}$ alt 1 malzemelerin $\mathrm{d}_{10}, \mathrm{~d}_{50}$ ve $\mathrm{d}_{90}$ tane boyut $(\mathrm{mm})$ değerleri

\begin{tabular}{lccc}
\hline \multicolumn{1}{c}{ Gölet } & $\mathrm{d}_{10}$ & $\mathrm{~d}_{50}$ & $\mathrm{~d}_{90}$ \\
\hline 4 No'lu & 0.00152 & 0.00634 & 0.0247 \\
Beke-Yörgüç & 0.00141 & 0.00639 & 0.0280 \\
6/C & 0.00125 & 0.00455 & 0.0166 \\
\hline
\end{tabular}

Tablo 1'deki verilerden de, 6/C gölet numunesinin 0.038 $\mathrm{mm}$ altındaki kısmının daha ince ve daha dar tane boyut dağılımına sahip olduğu sonucu ortaya çıkmaktadır. Bu verilerden elde edilen sonuçlar şöyle özetlenebilir:

- 4 No'lu gölet numunesinin üst tane boyutu en büyüktür (4 mm). Aynı zamanda ince tane oranı (-0.038mm) da oldukça yüksektir (\%69.55).

- 6/C gölet numunesinin üst tane boyutu daha küçüktür (2 mm). Aynı zamanda ince tane oranı da en düşüktür (\%26.52).

- Beke-Yörgüç gölet numunesinin ise hem üst tane boyutu en küçüktür $(0.5 \mathrm{~mm})$, hem de ince tane oranı en yüksektir (\%81.30). Yani daha dar tane boyut aralığına sahiptir.

\subsection{Kimyasal analizler}

\subsubsection{Elementel analiz}

4 No'lu, Beke-Yörgüç ve 6/C artık göletlerinden alınan orijinal ve $0.038 \mathrm{~mm}$ altı numunelerin analiz sonuçları sırasıyla Şekil 4 ve 5 'de verilmiştir. Şekil 4 ve 5 incelendiğinde her iki grup malzeme için de majör oksitlerin $\mathrm{SiO}_{2}, \mathrm{Al}_{2} \mathrm{O}_{3}, \mathrm{Fe}_{2} \mathrm{O}_{3}, \mathrm{CaO}, \mathrm{MgO}, \mathrm{K}_{2} \mathrm{O}$ ve $\mathrm{SO}_{3}$ olduğu görülmektedir. Bunların dışındaki $\mathrm{TiO}_{2}, \mathrm{Na}_{2} \mathrm{O}, \mathrm{NiO}, \mathrm{MnO}$, $\mathrm{P}_{2} \mathrm{O}_{5}$ ve $\mathrm{Cr}_{2} \mathrm{O}_{3}$ oksitlerinin değerleri ise \%1'in altındadır. $\mathrm{SiO}_{2}, \mathrm{Al}_{2} \mathrm{O}_{3}$ ve $\mathrm{Fe}_{2} \mathrm{O}_{3}$ 'ün yüksek konsantrasyonlarda izlenmesinin nedeninin; silis ve kil minerallerinden kaynaklandığı düşünülmektedir. En yüksek miktarlarda olan majör oksitlerden $\mathrm{SiO}_{2}, \mathrm{Al}_{2} \mathrm{O}_{3}$ ve $\mathrm{Fe}_{2} \mathrm{O}_{3}$ göz önüne alındığında (her iki grup malzeme için de) 4 No'lu gölet numunesinde bu oksitlerin en fazla miktarda olduğu görülmektedir. $\mathrm{SO}_{3}$ değerleri dikkate alındığında ise en yüksek değere $6 / \mathrm{C}$ gölet numunesi sahiptir. $\mathrm{Bu}$ sonuç bu numunenin en yüksek kükürt oranına sahip olmasından kaynaklanmaktadır. Orijinal numunelerin ateş zayiatı değerleri incelendiğinde ise yine en yüksek değere $6 / C$ gölet numunesinin sahip olduğu görülmektedir (Şekil 4). Bunun nedeni de bu gölet numunesinin kül oranının düşük olmasidir.

Ayrıca kil minerallerinin ana bileşenlerini oluşturan $\mathrm{SiO}_{2}, \mathrm{Al}_{2} \mathrm{O}_{3}$ ve $\mathrm{Fe}_{2} \mathrm{O}_{3}$ gibi oksitlerin oranının $0.038 \mathrm{~mm}$ altındaki malzemelerde arttığı dikkat çekmektedir. Bu sonuç da beklendiği gibi, kil minerallerinin $0.038 \mathrm{~mm}$ altında yoğunlaştığını ve en çok da 4 No'lu gölet numunesinde bulunduğunu göstermektedir. Bu malzemedeki kül oranının en yüksek olması da bu sonucu doğrulamaktadır (Tablo 2). 


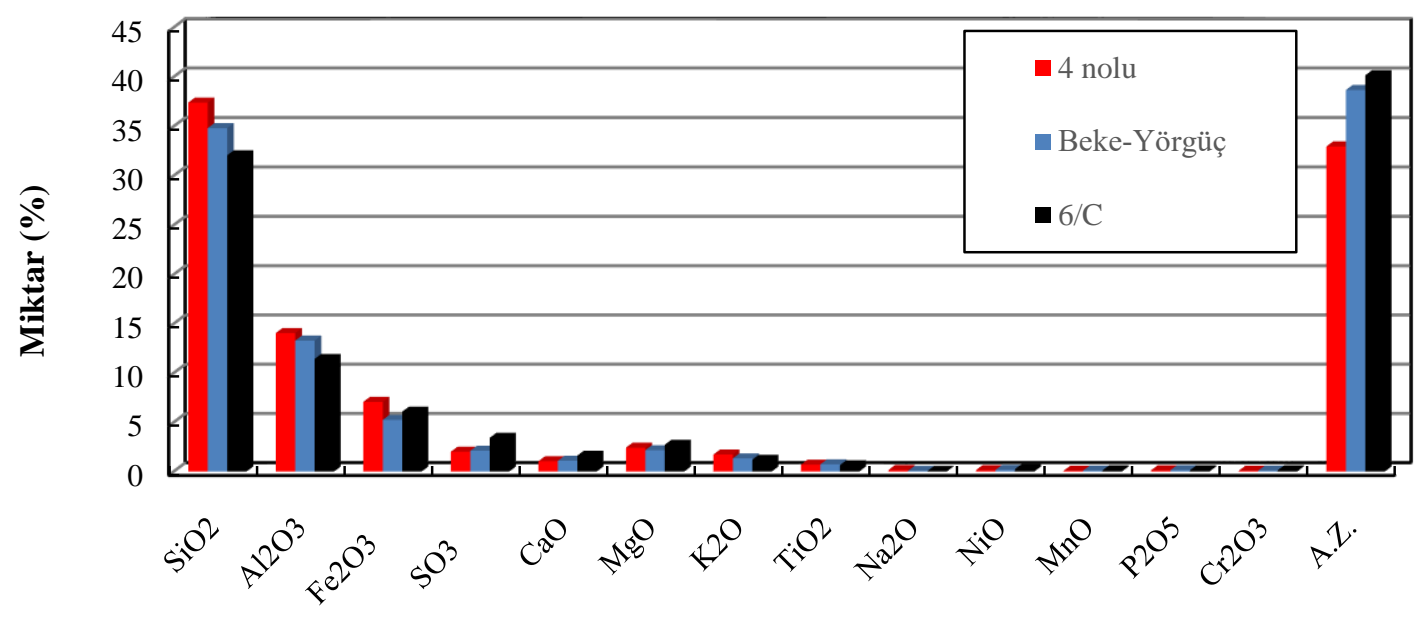

Bileşik

Şekil 4. Orijinal boyutlu malzemelerin elementel analizi

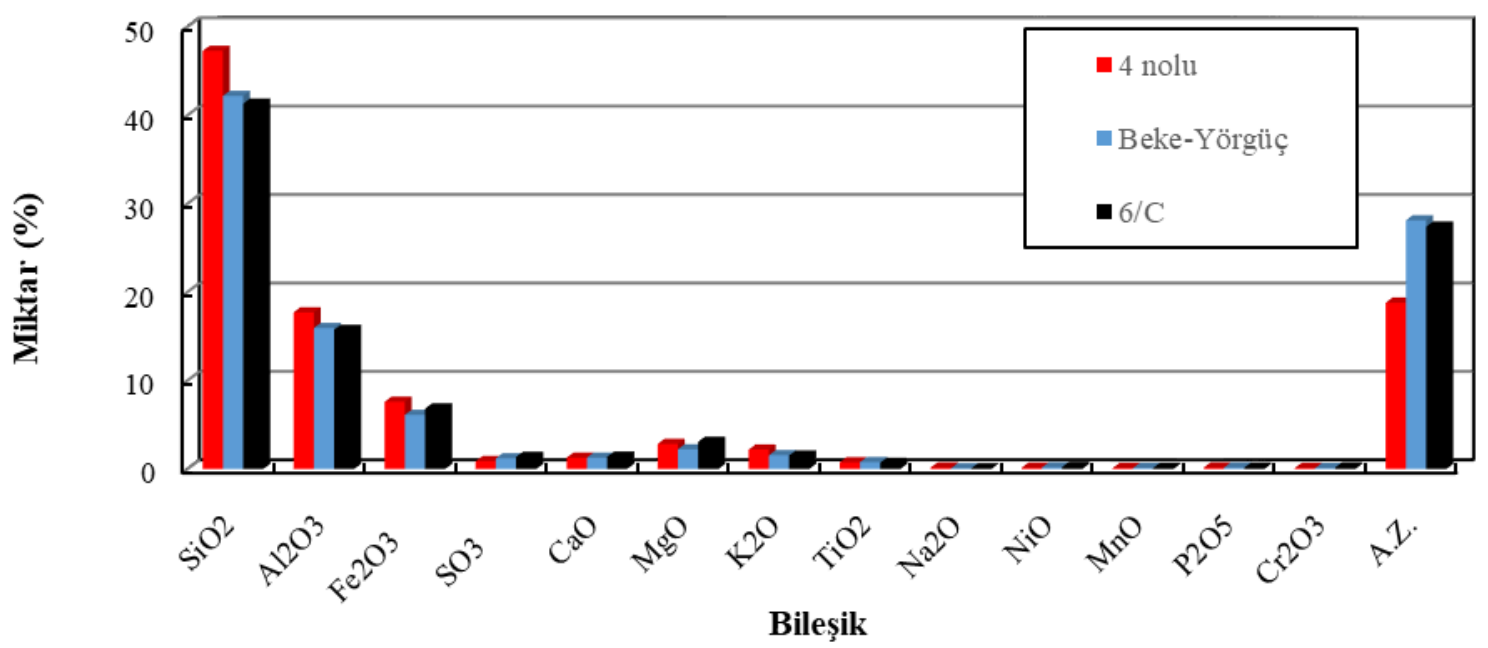

Şekil 5. $0.038 \mathrm{~mm}$ altı malzemelerin elementel analizi

Tablo 2. 4 No'lu gölet numunesinin nem, kül, kükürt ve 1sıl değerleri

\begin{tabular}{|c|c|c|c|c|c|c|}
\hline Tane Boyutu (mm) & Ağırlık (\%) & Kül (\%) & ÜID (Kcal/kg) & AID (Kcal/kg) & Kükürt (\%) & $\operatorname{Nem}(\%)$ \\
\hline+4 & 0.24 & 27.25 & 5191 & 4763 & 1.07 & 3.80 \\
\hline$-4+2$ & 1.50 & 24.83 & 5441 & 4944 & 1.16 & 4.70 \\
\hline$-2+1$ & 2.87 & 20.41 & 5731 & 5233 & 1.19 & 4.30 \\
\hline$-1+0.85$ & 0.24 & 25.45 & 5170 & 4710 & 1.23 & 4.30 \\
\hline$-0.85+0.6$ & 3.55 & 22.31 & 5468 & 4980 & 1.24 & 4.40 \\
\hline$-0.6+0.5$ & 1.61 & 26.00 & 5260 & 4803 & 1.28 & 4.20 \\
\hline$-0.5+0.425$ & 1.23 & 26.66 & 5031 & 4564 & 1.26 & 4.60 \\
\hline$-0.425+0.3$ & 1.52 & 33.64 & 4859 & 4451 & 1.20 & 4.00 \\
\hline$-0.3+0.212$ & 4.78 & 40.04 & 4519 & 4133 & 1.33 & 4.20 \\
\hline$-0.212+0.150$ & 1.86 & 37.78 & 4670 & 4251 & 1.33 & 4.60 \\
\hline$-0.150+0.106$ & 3.06 & 47.10 & 3933 & 3680 & 1.43 & 2.20 \\
\hline$-0.106+0.075$ & 1.35 & 48.03 & 3358 & 3086 & 1.39 & 3.10 \\
\hline$-0.075+0.063$ & 3.33 & 40.07 & 3598 & 3263 & 1.31 & 3.90 \\
\hline$-0.063+0.053$ & 0.93 & 50.69 & 3127 & 2870 & 1.12 & 3.10 \\
\hline$-0.053+0.038$ & 2.37 & 58.81 & 2531 & 2333 & 1.11 & 2.50 \\
\hline-0.038 & 69.55 & 81.91 & 653 & 601 & 0.34 & 1.70 \\
\hline Toplam & 100.00 & 68.01 & 1817.66 & 1665.04 & 0.62 & 2.35 \\
\hline
\end{tabular}


Tablo 3. Beke-Yörgüç gölet numunesinin nem, kül, kükürt ve 1sıl değerleri

\begin{tabular}{lllllll}
\hline Tane Boyutu $(\mathrm{mm})$ & Ağırlık (\%) & Kül (\%) & ÜID $(\mathrm{Kcal} / \mathrm{kg})$ & AID $(\mathrm{Kcal} / \mathrm{kg})$ & Kükürt $(\%)$ & Nem $(\%)$ \\
\hline+0.5 & 0.32 & 9.95 & 6773 & 6349 & 1.11 & 2.20 \\
$-0.5+0.425$ & 0.31 & 11.18 & 6563 & 6136 & 1.11 & 3.20 \\
$-0.425+0.3$ & 0.39 & 10.43 & 6622 & 6056 & 1.18 & 3.50 \\
$-0.3+0.212$ & 2.74 & 10.70 & 6586 & 6113 & 1.06 & 3.00 \\
$-0.212+0.150$ & 1.46 & 14.09 & 6492 & 6052 & 1.00 & 2.70 \\
$-0.150+0.106$ & 3.07 & 17.20 & 5888 & 5511 & 0.95 & 2.10 \\
$-0.106+0.075$ & 1.86 & 23.30 & 5321 & 4974 & 0.92 & 2.10 \\
$-0.075+0.063$ & 1.10 & 22.10 & 5304 & 4936 & 0.94 & 2.40 \\
$-0.063+0.053$ & 3.70 & 27.03 & 5164 & 4798 & 0.95 & 2.70 \\
$-0.053+0.038$ & 3.74 & 37.74 & 4285 & 4006 & 0.87 & 2.00 \\
-0.038 & 81.30 & 71.96 & 1257 & 1151 & 0.39 & 1.30 \\
Toplam & 100.00 & 62.73 & 2054.98 & 1898.44 & 0.50 & 1.51 \\
\hline
\end{tabular}

Tablo 4. 6/C gölet numunesinin nem, kül, kükürt ve 1sıl değerleri

\begin{tabular}{|c|c|c|c|c|c|c|}
\hline Tane Boyutu (mm) & Ağırlık (\%) & Kül (\%) & ÜID (Kcal/kg) & AID (Kcal/kg) & Kükürt (\%) & $\operatorname{Nem}(\%)$ \\
\hline+2 & 4.54 & 61.29 & 2347 & 2201 & 6.33 & 1.1 \\
\hline$-2+1$ & 16.50 & 62.13 & 2176 & 2021 & 3.27 & 1.6 \\
\hline$-1+0.5$ & 17.04 & 49.45 & 2533 & 2332 & 4.32 & 1.7 \\
\hline$-0.5+0.425$ & 4.12 & 48.61 & 2769 & 2568 & 5.98 & 1.5 \\
\hline$-0.425+0.3$ & 3.73 & 43.48 & 2643 & 2420 & 3.88 & 1.8 \\
\hline$-0.3+0.212$ & 9.87 & 54.35 & 2805 & 2614 & 3.28 & 1.7 \\
\hline$-0.212+0.106$ & 8.56 & 52.18 & 3058 & 2839 & 2.19 & 2.2 \\
\hline$-0.106+0.075$ & 3.24 & 57.33 & 3018 & 2814 & 2.46 & 2.2 \\
\hline$-0.075+0.063$ & 1.14 & 56.32 & 2934 & 2740 & 2.4 & 1.9 \\
\hline$-0.063+0.053$ & 2.38 & 51.30 & 3195 & 2970 & 2.12 & 2.2 \\
\hline$-0.053+0.038$ & 2.35 & 58.77 & 2547 & 2370 & 2.17 & 1.8 \\
\hline-0.038 & 26.52 & 74.25 & 1041 & 939 & 0.69 & 1.6 \\
\hline Toplam & 100.00 & 59.71 & 2191.94 & 2025.88 & 2.86 & 1.70 \\
\hline
\end{tabular}

Tablo 5. Orijinal ve $+0.038 \mathrm{~mm}$ boyutlu malzemelerin nem, kül, kükürt ve kalori değerleri

\begin{tabular}{|c|c|c|c|c|c|c|c|c|c|c|}
\hline \multirow{2}{*}{$\begin{array}{l}\text { Tane Boyl } \\
(\mathrm{mm})\end{array}$} & \multicolumn{2}{|c|}{$\operatorname{Nem}(\%)$} & \multicolumn{2}{|l|}{ Kül (\%) } & \multicolumn{2}{|c|}{ Kükürt (\%) } & \multicolumn{2}{|c|}{ ÜID (Kcal/kg) } & \multicolumn{2}{|c|}{ AID (Kcal/kg) } \\
\hline & Orijinal & $\begin{array}{l}+0.038 \\
\mathrm{~mm}\end{array}$ & Orijinal & $\begin{array}{l}+0.038 \\
\mathrm{~mm}\end{array}$ & Orijinal & $\begin{array}{l}+0.038 \\
\mathrm{~mm}\end{array}$ & Orijinal & $\begin{array}{l}+0.038 \\
\mathrm{~mm}\end{array}$ & Orijinal & $\begin{array}{l}+0.038 \\
\mathrm{~mm}\end{array}$ \\
\hline 4 No'lu & 2.35 & 3.84 & 68.01 & 36.27 & 0.62 & 1.27 & 1818 & 4478 & 1165 & 4095 \\
\hline Beke-Yörgüç & 1.51 & 2.44 & 62.73 & 22.59 & 0.50 & 0.96 & 2055 & 5525 & 1898 & 5148 \\
\hline $6 / \mathrm{C}$ & 1.70 & 1.74 & 59.71 & 54.47 & 2.86 & 3.64 & 2192 & 2607 & 2026 & 2418 \\
\hline
\end{tabular}

Tablo 5'den orijinal malzemelerin kül değerleri karşılaştırıldığında en yüksek kül değerine 4 No'lu göletin sahip olduğu görülmektedir. $0.038 \mathrm{~mm}$ üstü malzemelerin kül değerleri incelendiğinde ise, en yüksek kül değerine 6/C göletinin sahip olduğu görülmektedir. Bunun nedeni olarak bu malzemede $0.038 \mathrm{~mm}$ altına geçen kısmın (killi kısmın) azlığı gösterilebilir (Şekil 2). Yani kilin büyük bir bölümü 0.038 mm üzerinde kalmış, bu da kül miktarını artırmıştır. 4 No'lu gölet malzemesinde kül değeri en yüksek olmasına rağmen $0.038 \mathrm{~mm}$ elekten elendikten sonra kilin büyük bir bölümü elek altına geçmiş ve bu da kül miktarını düşürmüştür. Beke-Yörgüç göletinde ise bu durum daha belirgin olarak görülmektedir. Yani $-0.038 \mathrm{~mm}$ malzeme oranı yaklaşık \%80'dir (Şekil 2) ve bu da $+0.038 \mathrm{~mm}$ malzemesindeki kül değerinin \%22.59'a kadar düşmesine neden olmuştur. Aynı zamanda toplam kül değerlerinin, elementel analizlerden elde edilen kızdırma kaybı değerleri ile de örtüştüğü görülmektedir (Şekil 4 ve 5).

Tablo 5'den orijinal boyutlu malzemelerin 1sıl değerleri karşılaştırıldığında, en yüksek ısıl değere 6/C göletinin sahip olduğu görülmektedir. $+0.038 \mathrm{~mm}$ malzemelerin $1 \mathrm{~s} 1$ değerlerine bakıldığında ise 4 No'lu göletin ısıl değeri en düşük olmasına rağmen kül oranındaki azalışa bağlı olarak 1sıl değerinin önemli oranda arttığ dikkat çekmektedir. En düşük kül oranına sahip olan Beke-Yörgüç göletinin +0.038 $\mathrm{mm}$ boyutlu kısmı ise en yüksek 1sıl değerlere sahip olmuştur.

Yine Tablo 5'den en yüksek toplam kükürt değerinin 6/C göleti numunelerinden (orijinal ve $+0.038 \mathrm{~mm}$ ) elde edildiği dikkat çekmektedir. Aynı zamanda bu sonuçların, elementel analizden elde edilen kükürt değerleri ile de uyumlu olduğu görülmektedir (Şekil 4 ve 5).

\subsubsection{Mineralojik analiz}

Göletlerden alınan numunelerin mineralojik bileşimlerinin belirlenmesi amaciyla XRD analizleri yapılmıştır. Orijinal malzemelerinin ve $-0.038 \mathrm{~mm}$ boyutlu malzemelerin XRD paternleri sirasıyla Şekil 6 ve 7'de verilmiştir.

Şekil 6 ve 7 incelendiğinde hem orijinal hem de 0.038 $\mathrm{mm}$ altı malzemelerde tanımlanan başlıca minerallerin kuvars, muskovit/illit, montmorillonit, kristobalit, kaolinit ve jips olduğu görülmektedir. 


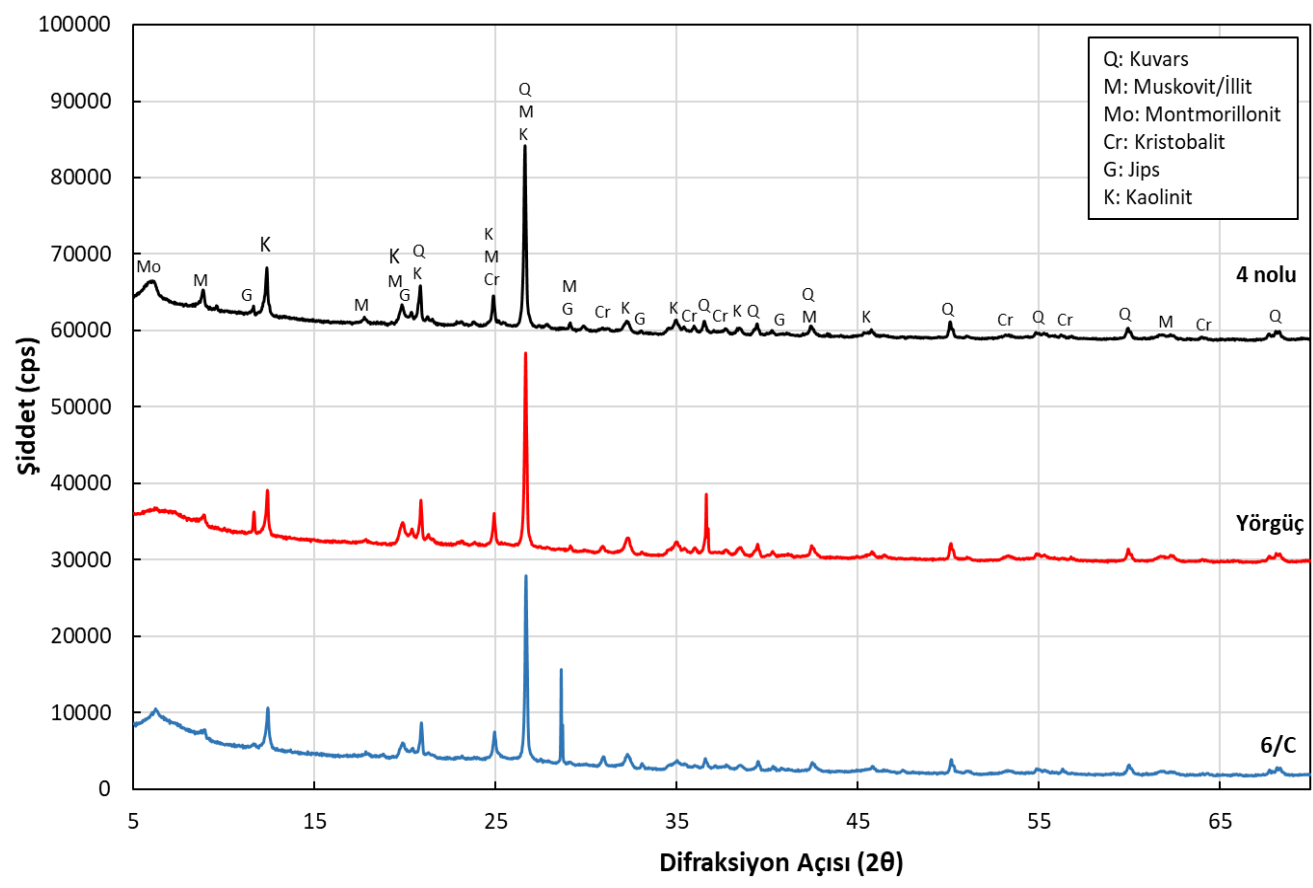

Şekil 6. Orijinal boyutlu malzemelerin XRD paternleri

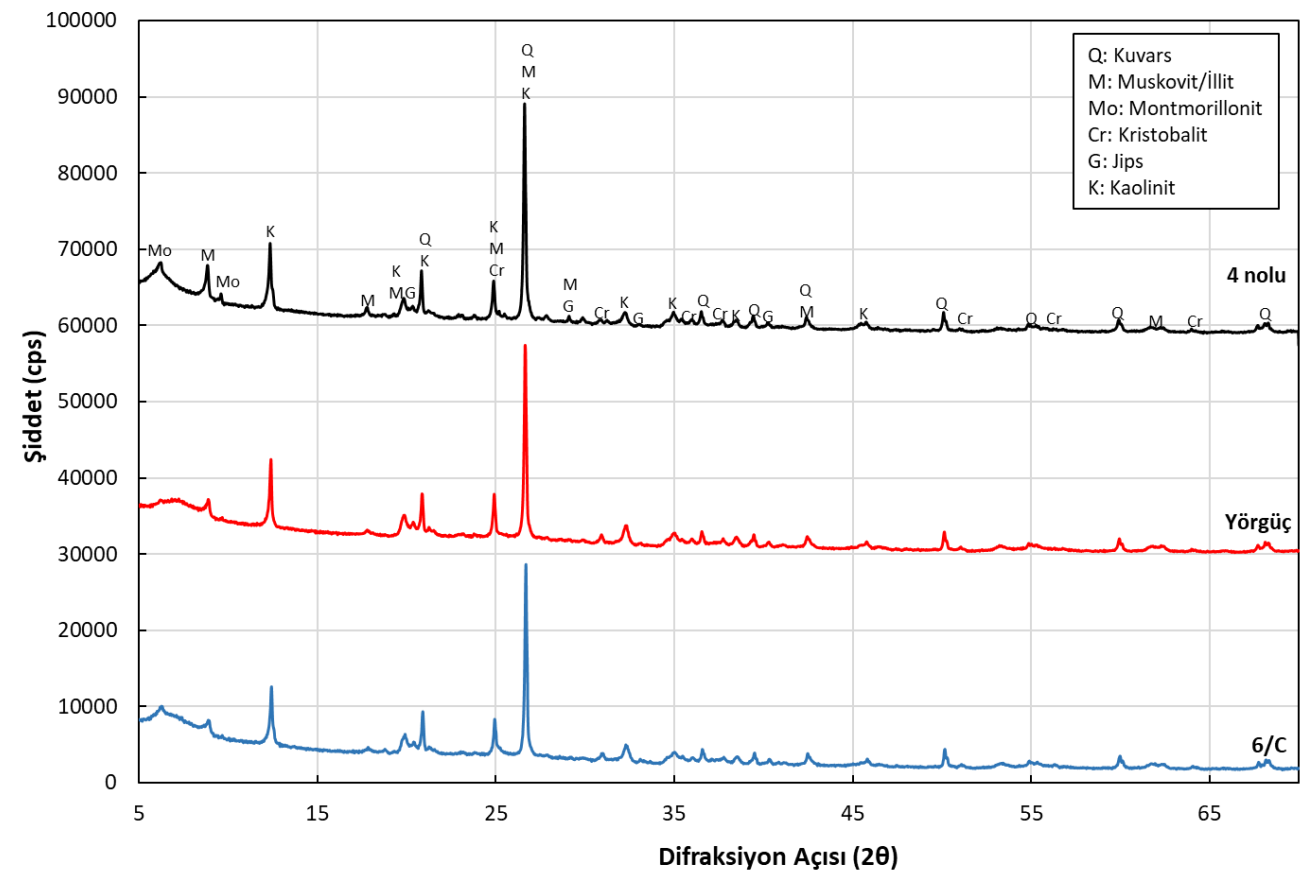

Şekil 7. $0.038 \mathrm{~mm}$ altı malzemelerin XRD paternleri

\subsubsection{Termal analiz}

Gölet numunelerinin TG-DTA analiz sonuçları Şekil 8 ve 9'da verilmiştir.

Şekil 8 ve 9'dan TG eğrileri incelendiğinde tüm gölet malzemelerinde $200{ }^{\circ} \mathrm{C}$ 'ye kadar yaklaşık \%1-1.7 arasındaki oranlarda bir ağırlık kaybının olduğu görülmektedir. Bu kayıplar artıklardaki ortam neminin uzaklaşmasından kaynaklanmaktadır. $300-600{ }^{\circ} \mathrm{C}$ arasında yaklaşı $\% 7-10$ oranlarında büyük ağırlık kayıpları izlenmektedir. Bu da artıklardaki organiklerin ve killerde bulunan kristal suların uzaklaşmasından kaynaklanmaktadır. $600{ }^{\circ} \mathrm{C}$ 'den sonra hala ağırlık kayıplarının devam ettiği fakat daha az olduğu görülmektedir. $\mathrm{Bu}$ da bu sicaklıktan sonra organik madde uzaklaşmasının devam ettiğini göstermektedir.

DTA eğrileri incelendiğinde ise $200-400{ }^{\circ} \mathrm{C}$ arasında tüm numunelerde ekzotermik pikler oluştuğu görülmektedir. Bu durum organik maddelerin yanma reaksiyonlarından kaynaklanmaktadir. 


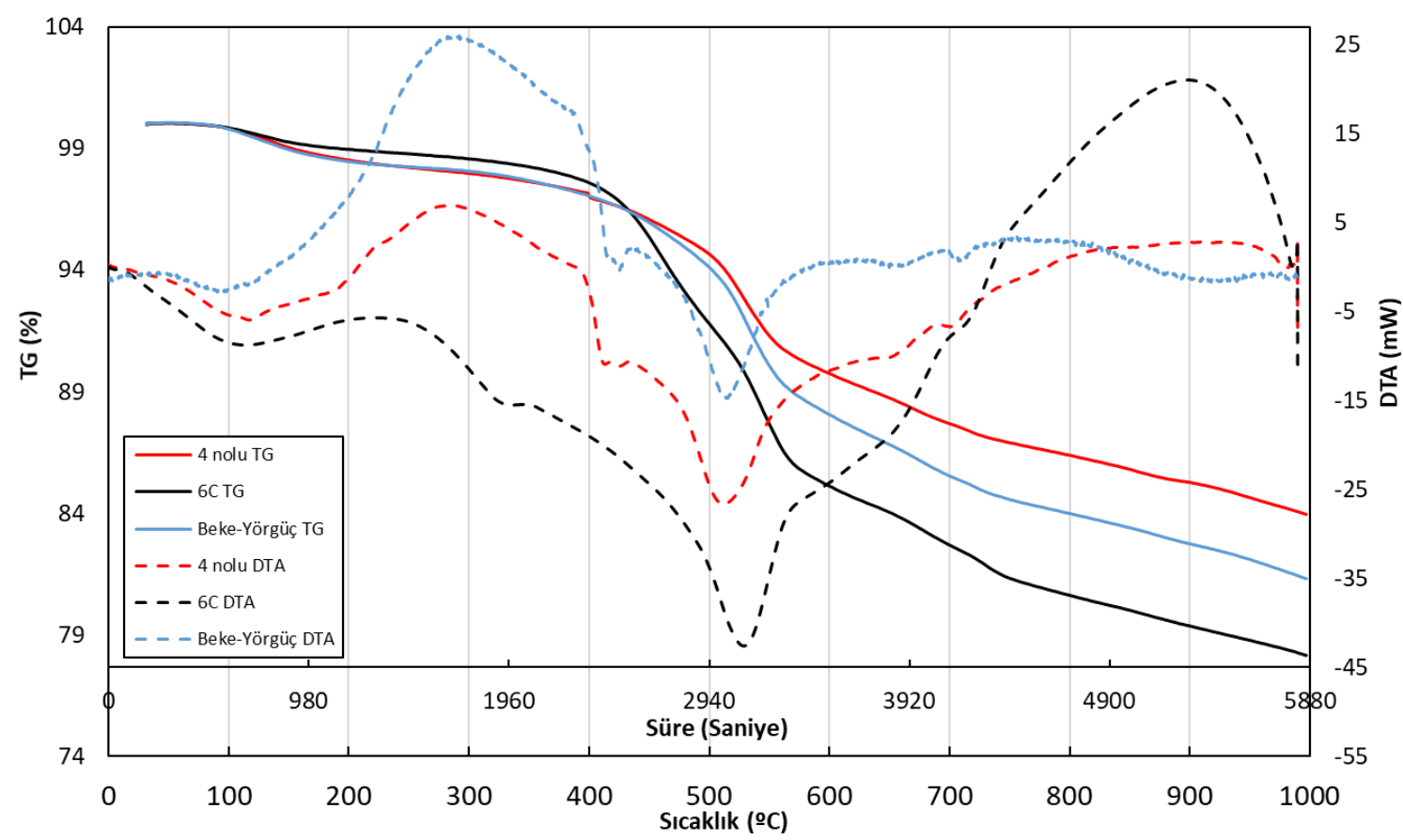

Şekil 8. Orijinal boyutlu malzemelerin TG-DTA analiz sonuçları

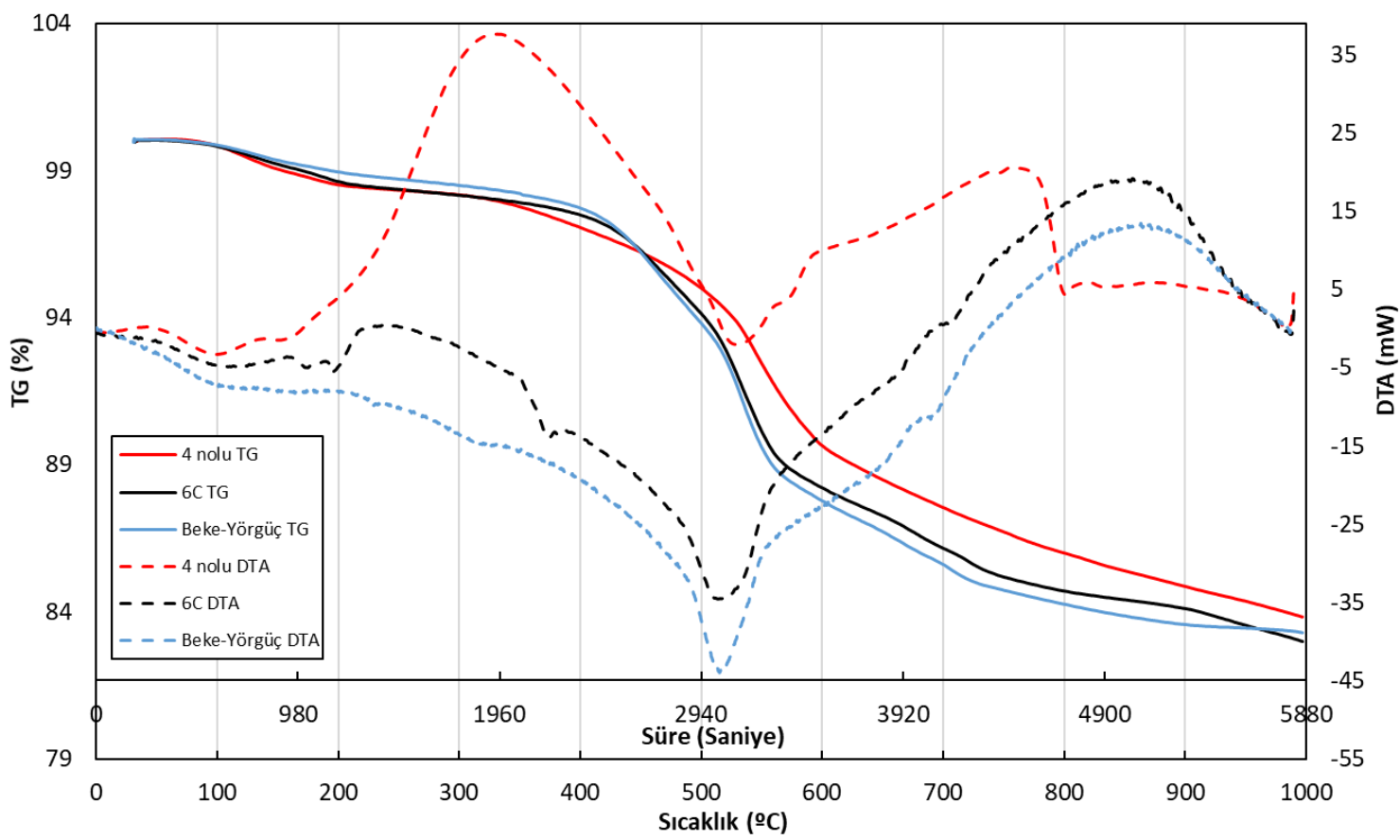

Şekil 9. $0.038 \mathrm{~mm}$ altı malzemelerin TG-DTA analiz sonuçları

500-550 ${ }^{\circ} \mathrm{C}$ 'ler arasında ise endotermik pikler oluşmaktadır. $\mathrm{Bu}$ durum da kil minerallerinin kristal sularının uzaklaşmasının bir sonucudur. $690-750{ }^{\circ} \mathrm{C}$ 'ler arasında küçük endotermik pikler görülmektedir. Bunun da kömürdeki kükürdün uzaklaşmasından kaynaklandığı düşünülmektedir. $800-900{ }^{\circ} \mathrm{C}$ arasında ise büyük ve geniş ekzotermik pikler gözlenmektedir. $\mathrm{Bu}$ durum kil minerallerinin kristal yapılarındaki düzenlenme nedeniyle oluşmaktadır. $\mathrm{Bu}$ sicaklıktan sonra kristalleşme tamamlanmakta ve tekrar ısı alarak malzeme erime eğilimine girmektedir.

\section{Sonuçlar ve öneriler}

$\mathrm{Bu}$ çalışmada GLİ (Kütahya) bünyesinde faaliyet gösteren Tunçbilek ve Ömerler lavvar tesislerinden açığa çıkan ve imalatı yapılmış açık ocak çukurlarında depolanmış bulunan, 4 No'lu, Beke-Yörgüç ve $6 / C$ olarak adlandırılan 
şlam artıklarının karakterizasyonunun belirlenmesine çalışılmıştır. Elde edilen sonuçlar aşağıda özetlenmiştir.

- Numunelerin elek analizi sonuçlarına göre; 4 No'lu göletin en büyük tane boyutu $4 \mathrm{~mm}, 6 / \mathrm{C}$ gölet numunesinin $2 \mathrm{~mm}$ ve Beke-Yörgüç gölet malzemesinin ise $0.5 \mathrm{~mm}$ olduğu saptanmıştır. 0.038 mm altı malzeme oranı 4 No'lu gölet şlamında $\% 69.55$, Beke-Yörgüç gölet şlamında \%81.30 iken 6/C gölet şlamının \%26.52 olduğu belirlenmiştir. $0.038 \mathrm{~mm}$ altı malzemenin boyut dağılımına göre ise $6 / \mathrm{C}$ gölet numunesinin daha ince tane boyut dağllımına sahip olduğu belirlenmiştir.

- Numunelerin elementel analizlerine göre majör oksitlerin $\mathrm{SiO}_{2}, \mathrm{Al}_{2} \mathrm{O}_{3}, \mathrm{Fe}_{2} \mathrm{O}_{3}, \mathrm{CaO}, \mathrm{MgO}, \mathrm{K}_{2} \mathrm{O}$ ve $\mathrm{SO}_{3}$ olduğu belirlenmiştir.

- Numunelerin kül değerlerinin yüksek, kalori değerlerinin düşük olduğu tespit edilmiştir. 0.038 mm'den daha iri boyutlarda kükürt değerlerinin ise daha fazla olduğu belirlenmiştir.

- Orijinal numune ve $0.038 \mathrm{~mm}$ altı tüm numunelerin kuvars, muskovit/illit, montmorillonit, kristobalit, jips, kaolinit minerallerinden oluştuğu tespit edilmiştir.

- DTA-TG analiz sonuçlarına göre, tüm malzemelerde sıcaklığın artmasıyla uçucu maddeler ve kömür yanması başlamış ve bu durum $800^{\circ} \mathrm{C}$ 'ye kadar devam etmiştir. $690-750^{\circ} \mathrm{C}$ arasında ise kömürdeki kükürdün uzaklaştığı belirlenmiştir.

- 0.038 mm'den daha iri boyutlu artık malzemelerde önemli oranda kömür bulunduğu ve bu kömürün kazanılarak ekonomik kayıpların önlenebileceği tespit edilmiştir.

- $0.038 \mathrm{~mm}$ 'den daha ince boyutlu artık malzemelerin ise (özellikle 4 No'lu ve Beke-Yörgüç atıklarının daha fazla ince tane ve daha az kükürt içermeleri nedeniyle) tuğla-kiremit ve kaplama malzemesi üretiminde hammadde olarak kullanılabileceği ortaya çıkmıştır. 6/C gölet malzemesinin yüksek oranda kükürt içermesi, gözenekli ve hafif yapı malzemesi üretiminde avantaj sağlayacaktır.

- $\mathrm{Bu}$ artık malzemelerin tuğla-kiremit, kaplama, terracotta ve çimento sektörlerinde kullanılmasıyla hem çevresel sorunlar büyük ölçüde önlenecek hem de bu malzemelere katma değer kazandırılacaktır.

- İleride yapılacak çalışmalarda, renk probleminin tolere edilebileceği seramik bünye üretimimde, 4 No'lu ve Beke-Yörgüç atıklarının kullanılabilirliği araştırılarak bu atıkların değerlendirilme alanı genişletilebilir.

\section{Teşekkür}

$\mathrm{Bu}$ çalışmada katkılarından dolayı Türkiye Kömür İşletmeleri Garp Linyitleri İşletmesi Müessese Müdürlüğü yetkililerine teşekkür ederiz.

\section{Çıkar çatışması}

Yazarlar çıkar çatışması olmadığını beyan etmektedir.

Benzerlik oranı (iThenticate): $\% 11$

\section{Kaynaklar}

[1] R. A. Meyers, J. S. Laskowski, and A. D. Walters, Coal Preparation. in: Encyclopedia of physical science and technology. R. A. Meyers (Eds.), Academic Press, pp. 277, California, 2001.

[2] G. F. Meenan, Modern Coal Flotation Practices. In: Advances in Flotation Technology. Parekh and Miller (Eds.), SME, pp. 309-321, Denver, 1999.

[3] A. Güney, G. Ateşok, G. Önal ve A. Altaş, Kömür Zenginleştirme Teknolojisindeki Yenilikler. in: III. Kömür Teknolojisi ve Kullanımı Semineri Kitabı. Önal ve Ateşok (Ed.), Yurt Madenciliği Geliştirme Vakfi Yayınları, sayfa 270-282, İstanbul, 1996.

[4] B. J. Arnold, Rate and Residence Time Studies Applied to the Operation of Conventional Coal Froth Flotation Cells. In: Advances In Flotation Technology. Parekh and Miller (Eds.), SME, pp. 321-331, Denver, 1999.

[5] İ. Kafadar, Açık işletmelerde toprak ve çevre tahribi ile arazinin yeniden düzenlenmesi. Türkiye 8 . Komür Kongresi, sayfa 552-560, Zonguldak, Türkiye, 22-23 Şubat 1992.

[6] Garp Linyitleri İşletmesi Komisyonu, Şlam Değerlendirme Komisyon Raporu. Garp Linyitleri İşletmesi, Kütahya, Türkiye, Teknik Rapor, 15 Eylül 2017.

[7] F. S. Karaoğuz, Kömür hazırlama tesis atıklarının değerlendirilmesi. Yüksek Lisans Tezi, Hacettepe Üniversitesi Fen Bilimleri Enstitüsü, Türkiye, 2017.

[8] H. Çiftçi ve S. Işık, İnce boyutlu lavvar tesisi atıklarının anyonik flokülantlar ile susuzlandırılmasında çeşitli parametrelerin etkisi. AKÜ FEMÜBİ, 16, 391-398, 2016. https://dergipark.org.tr/tr/download/articlefile/652464

[9] İ. Bentli, Kömür lavvar tesisi atıkların flokülasyonunda inorganik elektrolitlerin etkisi. Ekoloji, 19 (76), 71-77, 2010. https://doi.org/10.5053/ekoloji.2010.768

[10] M. F. Eskibalci ve M. F. Özkan, Kömür hazırlama tesis artıklarının koagülasyon ile susuzlandırılmasında farklı koagülant tiplerinin etkisinin araştırılması. BAUN Fen Bil. Enst. Dergisi, 21(1), 43-52, 2019. https://dergipark.org.tr/en/download/articlefile/657890

[11] M. Karaoğlu, TKİ Alpagut-Dodurga linyitleri işletmesi şlamlarından kömürün kazanılması. Yüksek Lisans Tezi, Eskişehir Osmangazi Üniversitesi Fen Bilimleri Enstitüsü, Türkiye, 1999.

[12] N. T. Sayin, Tesis atığından kömür kazanımının incelenmesi. Yüksek Lisans Tezi, Sivas Cumhuriyet Üniversitesi Fen Bilimleri Enstitüsü, Türkiye, 2019.

[13] Ö. Yaşar, T. Uslu and E. Şahinoğlu, Recovery of fine coals from tailings of Tunçbilek coal washery by oil agglomeration (Preliminary study). 15th International Mineral Processing Symposium, 985-992, İstanbul, Türkiye, 19-21 Ekim 2016.

[14] S. Özgen, Z. Arsoy, B. Ersoy ve H. Çiftçi, Lavvar tesisi tikiner atığından kömürün geri kazanımı. DÜMF Mühendislik Dergisi, 10(2), 663-674, 2019. https://dergipark.org.tr/en/download/articlefile/738438 
[15] E. Sabah, Kil İçerikli Kömür Hazırlama Tesisi Atıklarından Temiz Kömür Üretimi ve Atık Kilin Tuğla Üretiminde Kullanılabilirliğinin Araştırılması. TÜBİTAK, MAG-1041080, 2005.

[16] A. S. İnce, Tuğla bünyesinde kömür artığı ve bor kullanımının araştırılması. Yüksek Lisans Tezi, Dumlupınar Üniversitesi Fen Bilimleri Enstitüsü, Türkiye, 2019.

[17] TÜBİTAK MAM, Tunçbilek lavvarı şlam atıklarının tuğla ve çimento üretiminde hammadde olarak değerlendirilmesi. https://me.mam.tubitak.gov.tr/ tr/haber/tuncbilek-lavvari-slam-atiklarinin-tugla-vecimento-uretiminde-hammadde-olarak, 01.02 .2021

Erişim 